\title{
Quantitative and enantioselective analysis of monoterpenes from plant chambers and in ambient air using SPME
}

\author{
N. Yassaa ${ }^{1,2}$, T. Custer ${ }^{1}$, W. Song ${ }^{1}$, F. Pech ${ }^{3}$, J. Kesselmeier ${ }^{3}$, and J. Williams ${ }^{1}$ \\ ${ }^{1}$ Air Chemistry Department, Max-Planck Institute for Chemistry, J. J. Becher Weg 27, 55020 Mainz, Germany \\ ${ }^{2}$ Faculty of Chemistry, University of Sciences and Technology Houari Boumediene, U.S.T.H.B., B.P. 32 El-Alia, \\ Bab-Ezzouar, 16111 Algiers, Algeria \\ ${ }^{3}$ Biogeochemistry Department, Max-Planck Institute for Chemistry, J. J. Becher Weg 27, 55020 Mainz, Germany
}

Received: 20 July 2010 - Published in Atmos. Meas. Tech. Discuss.: 9 August 2010

Revised: 8 November 2010 - Accepted: 16 November 2010 - Published: 23 November 2010

\begin{abstract}
A headspace solid-phase microextraction (HS-SPME) and gas chromatography/mass spectrometry (GC/MS) system has been developed for quantifying enantiomeric and nonenantiomeric monoterpenes in plant chamber studies and ambient air. Performance of this system was checked using a capillary diffusion system to produce monoterpene standards. The adsorption efficiency, competitive adsorption and chromatographic peak resolution of monoterpene enantiomer pairs were compared for three SPME fibre coatings: $75 \mu \mathrm{m}$ CarboxenPDMS (CAR-PDMS), 50/30 $\mu \mathrm{m}$ divinylbenzene-carboxenpolydimethylsiloxane (DVB-CAR-PDMS) and $65 \mu \mathrm{m}$ divinylbenzene-polydimethylsiloxane (DVB-PDMS). Key parameters such as the linearity and reproducibility of the SPME system have been investigated in this work. The best compromise between the enantiomeric separation of monoterpenes and competitive adsorption of the isoprenoids on the solid SPME fibre coating was found for DVB-PDMS fibres. The optimum conditions using DVB-PDMS fibres were applied to measure the exchange rates of monoterpenes in the emission of Quercus ilex using a laboratory whole plant enclosure under light and dark conditions, as well as in ambient air. With 592 and $223 \mathrm{ng} \mathrm{m}^{-2} \mathrm{~s}^{-1}$ respectively, $\beta$-myrcene and limonene were the predominant monoterpenes in the emission of $Q$. ilex. These values were closely comparable to those obtained using a zNose and cartridge GC-FID systems.
\end{abstract}

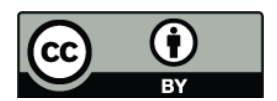

Correspondence to: N. Yassaa (nyassaa@usthb.dz)

\section{Introduction}

Biogenic emissions of volatile organic compounds (VOCs) are estimated to exceed anthropogenic emissions by roughly a factor of ten on the global scale (Guenther et al., 1995; Müller, 1992). Due to the high reactivity of BVOC with the primary oxidizing agent $\mathrm{OH}$ and their propensity to form particles, these emissions can affect global oxidation chemistry and the Earth's radiation budget (Williams 2004 and references therein). One much studied sub-set of BVOC is the family of monoterpenes, which are emitted by terrestrial plants to the atmosphere in large amounts (ca. $150 \mathrm{TgC}_{\text {year }}{ }^{-1}, \mathrm{Tg}=10^{12} \mathrm{~g}$ ) (Guenther et al., 1995). Monoterpenes are particularly important in atmospheric chemistry, reacting rapidly with ozone, $\mathrm{NO}_{3}$ and $\mathrm{OH}$, often leading to the production of secondary organic particles in significant yield. Their function in the natural world may be as a signaling compound for insects, aiding pathogen and pollinators alike in finding plants. They might also act as a chemical defense against various insects as well as play a role in inter plant communication (Croteau, 1987; Baldwin et al., 2006; Unsicker et al., 2009). Most of these monoterpenes are chiral, although in most atmospheric chemistry studies the $(+)$ - and (-)-enantiomers are not resolved and hence measured together (e.g. Kesselmeier and Staudt, 1999). While the gas phase reaction rates of both enantiomers are identi$\mathrm{cal}$, the individual enantiomers often have markedly different biological properties (Lough, 2002). Interestingly, it has been recently reported that optical isomers can react at significantly different rates when they are adsorbed on the surface of aerosol (Stokes et al., 2009).

Published by Copernicus Publications on behalf of the European Geosciences Union. 
Reliable and quantitative methods are needed for the analysis of chiral monoterpenes in order to evaluate to what extent different optical isomers contribute to formation of secondary organic aerosols (SOA), to understand the metabolic processes underlying their release, and to study their ambient distribution. To date, little work has been done to analyze naturally occurring enantiomeric gas phase biogenic emissions. Specific plant emissions have been investigated previously using a $\beta$-cyclodextrin capillary GC with charcoal adsorption/solvent extraction (Yassaa et al., 2000), and carbograph adsorption/thermal desorption (Yassaa et al., 2001; Williams et al., 2007). In our previous works, we have reported on the applicability of SPME for qualitative study of the biogenic emission of enantiomeric and nonenantiomeric monoterpenes from living plants (Yassaa and Williams, 2005, 2007). For the first time, we present a quantitative method to measure enantiomeric and nonenantiomeric monoterpenes using SPME to extract monoterpenes. The SPME system was calibrated using standards generated by a home-built capillary diffusion system. Three different SPME fibre coatings were tested, including $75 \mu \mathrm{m}$ Carboxen-PDMS (CAR-PDMS), 50/30 $\mu$ m divinylbenzenecarboxen-polydimethylsiloxane (DVB-CAR-PDMS), and $65 \mu \mathrm{m}$ divinylbenzene-polydimethylsiloxane (DVB-PDMS). Each of these coatings were compared with regard to their adsorption efficiency, competitive adsorption effects and achievable chromatographic peak resolution for pairs of monoterpene enantiomers. Key parameters such as the evolution of the extraction efficiencies as a function of sampling time, the linearity of SPME adsorption and detection limit were also investigated in the course of this work. An optimised method was then employed to measure enantiomeric and nonenantiomeric monoterpenes emitted by Quercus ilex in laboratory whole plant enclosure as well as in ambient air. A comparison of simultaneous measurements of these emissions using SPME, solid sorbent GC-FID and a zNose (fast chromatograph equipped with a surface acoustic wave sensor) provide further validation of this method.

\section{Experimental}

\subsection{SPME}

\subsubsection{Standard generation}

Monoterpene standards were generated using a 5 channel capillary diffusion system (CDS) as displayed in Fig. 1, which employs similar principle as that used by e.g., Helmig et al. (2003) and Baker and Sinnott (2009). Briefly, this system consists of an aluminium block fitted with 2 peltier elements for temperature regulation (maintained for these experiments at $27 \pm \sim 0.02{ }^{\circ} \mathrm{C}$ using custom built PID regulation system) and drilled through to house five glass chambers. Glass chambers ( $160 \mathrm{~mm}$ length, $2.22 \mathrm{~mm}$ o.d., $1.9 \mathrm{~mm}$

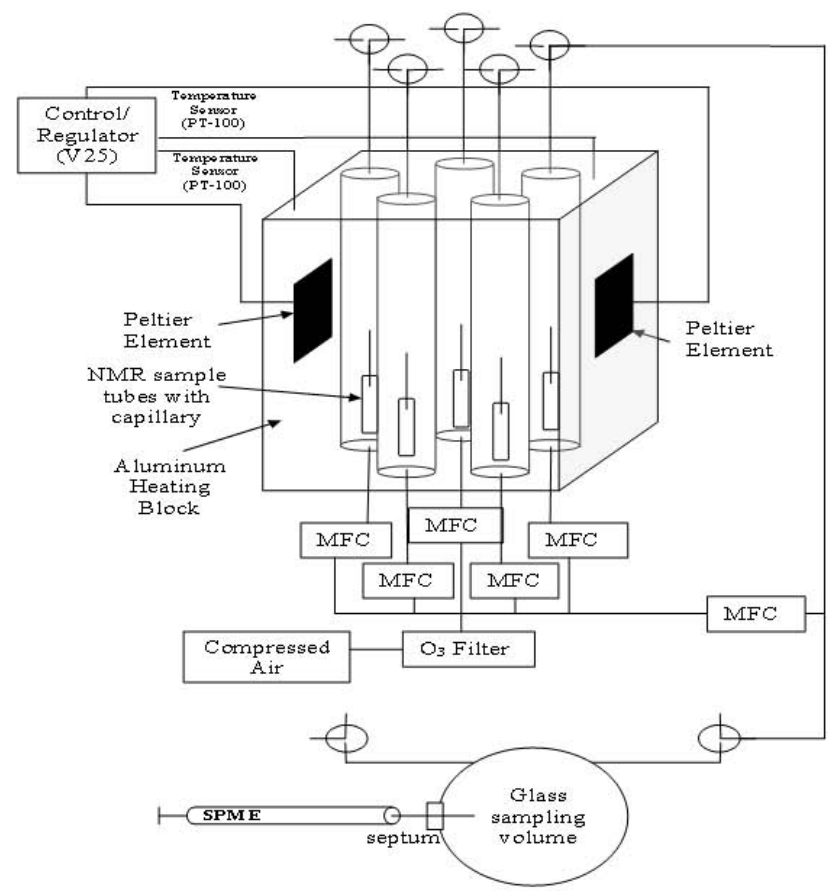

Fig. 1. Schematic representation of capillary diffusion system (CDS) and glass sampling chamber. Aluminum block is maintained at $27^{\circ} \mathrm{C}$ by either heating or cooling the peltier elements. Entire aluminum block is surrounded by a thick layer of insulation material and peltiers are connected to large cooling vanes to effectively dissipate heat. Tubing leading to the glass chambers is pre-heated to equilibrate air temperature prior to entry into the glass chamber. MFC: mass flow controller. V25: a MPI custom built control/regulator.

i.d.) are fitted with custom built Teflon end caps accommodating insertion of $0.32 \mathrm{~nm}(1 / 8 \mathrm{inch})$ tubing. A regulated flow ( $\sim 50$ SCCM, see Table 1, maintained by MKS mass flow controllers) of compressed air was passed through two ozone scrubbers to avoid any oxidation of monoterpene species and then through each of these chambers independently. The ozone scrubbers were prepared by flowing 10 $\mathrm{mL}$ of a $10 \%[\mathrm{w} / \mathrm{w}]$ aqueous solution of $\mathrm{Na}_{2} \mathrm{~S}_{2} \mathrm{O}_{3}$ through $47 \mathrm{~mm}$ diameter glass fiber filter disks and subsequent drying under a nitrogen purge flow of $80 \mathrm{~mL} \mathrm{~min}^{-1}$ at $50{ }^{\circ} \mathrm{C}$ for $4 \mathrm{~h}$ (Pollman et al., 2005). Approximately $500 \mu \mathrm{L}$ of selected pure monoterpene standards (Sigma-Aldrich, Germany) were placed separately in vials ( $5 \mathrm{~mm}$ quartz NMR tubes, Kontes glass company 897193-0050) and capped using standard NMR caps. The vials were then placed individually into the larger glass chambers, see Fig. 1. A deactivated diffusion capillary $(0.53 \mathrm{~mm}$ i.d., $5 \mathrm{~cm}$ length, PhenylSil-Deactivation) was fed through the cap of each vial to allow a limited amount of chemical to diffuse into the air flowing through each chamber. Output of the CDS was further diluted by mixing the output of the system with a stream of clean compressed air whose flow rate was controlled by a 
Table 1. Mixing ratios of monoterpenes from the standard gas bottle, measured from CDS and calculated from the weight loss of CDS tubes.

\begin{tabular}{|c|c|c|c|c|c|}
\hline & \multirow{2}{*}{$\begin{array}{l}\text { Gas standard } \\
\text { bottle }\end{array}$} & \multicolumn{4}{|l|}{$\mathrm{CDS}$} \\
\hline & & Channel & $\begin{array}{l}\text { Flow rate } \\
(\mathrm{SCCM})\end{array}$ & $\begin{array}{l}\text { Measured Mixing } \\
\text { ratios }(\mathrm{ppm}) \\
\text { for CDS }\end{array}$ & $\begin{array}{l}\text { Theoretical mixing ratios } \\
\text { (ppm) from weight loss } \\
\text { of CDS tubes }\end{array}$ \\
\hline$(1 S)-(-)-\alpha$-Pinene & $2.00 \pm 0.06$ & 1 & 58.35 & $1.75 \pm 0.07$ & 2.06 \\
\hline$(1 S)-(-)-\beta$-Pinene & $1.98 \pm 0.06$ & 1 & & $2.01 \pm 0.07$ & 2.51 \\
\hline$(4 S)-(-)$-Limonene & $2.05 \pm 0.06$ & 1 & & $1.56 \pm 0.08$ & 1.75 \\
\hline$\beta$-Myrcene & $1.92 \pm 0.10$ & 2 & 53.64 & $2.27 \pm 0.11$ & 1.66 \\
\hline$(+)-\delta$-3-Carene & $1.99 \pm 0.06$ & 2 & & $1.24 \pm 0.07$ & 1.62 \\
\hline 1.8-Cineol & $2.18 \pm 0.11$ & 2 & & $1.49 \pm 0.12$ & 1.65 \\
\hline$(1 R)-(+)-\alpha$-Pinene & $2.00 \pm 0.06$ & 3 & 54.64 & $1.84 \pm 0.07$ & 2.17 \\
\hline$(1 R)-(+)-\beta$-Pinene & $1.98 \pm 0.06$ & 3 & & $2.14 \pm 0.07$ & 1.87 \\
\hline$(4 R)-(+)$-Limonene & $2.05 \pm 0.06$ & 3 & & $2.10 \pm 0.08$ & 1.81 \\
\hline
\end{tabular}

mass flow controller. The weight loss of chemical over time was monitored every few weeks, thus allowing calculation of the theoretical mixing ratio emanating from the CDS. The output of the CDS was also directly measured and compared to measurements of a trace gas standard (National Physical Laboratory, Teddington Middlesex, UK). Results of this comparison are given in Table 1.

\subsubsection{SPME sampling chamber}

For SPME sampling (see Fig. 1), a small septum (SigmaAldrich, Supelco, Germany) as well as two $0.64 \mathrm{~cm}$ (1/4 inch) glass ports (inlet and outlet) with teflon stopcocks were affixed to a $5 \mathrm{~L}$ glass chamber (Skötch, Mainz, Germany). The $5 \mathrm{~L}$ volume of the chamber was sufficient to homogeneously mix the analytes prior to SPME sampling. Mixing was initially tested using two $250 \mathrm{~mL}$ gas sampling bulbs (Supelco) individually or in series. When sampling from the CDS or standard gas bottle, upon changing chemical mixing ratios the system was allowed to reach steady state by allowing gas to flow through the system for at least an hour. After a steady state was attained, the stopcocks were closed isolating the collected, equilibrated air. The monoterpenes were sampled from the glass chamber, by piercing the septum and exposing the fibre to the equilibrated air for a measured time. Temperature during measurements remained essentially constant at $25^{\circ} \mathrm{C}$ in the climate controlled laboratory. Immediately following exposure, the fibres were analysed by GC-MS. The time between SPME sampling and GC-MS analysis never exceeded $3 \mathrm{~min}$. Each SPME sampling was repeated at least 3 times. After SPME sampling, the system was again flushed by re-opening the two stopcocks.

\subsection{Comparison of SPME fibre coatings}

Three SPME fibre coatings were selected for testing and were all obtained from Supelco (Taufkirchen, Germany). The fibres tested included $75 \mu \mathrm{m}$ CarboxenPDMS (CAR-PDMS), 50/30 $\mu \mathrm{m}$ divinylbenzene-carboxenpolydimethylsiloxan (DVB-CAR-PDMS) and $65 \mu \mathrm{m}$ divinylbenzene-polydimethylsiloxane (DVB-PDMS). These were chosen based on previous experience with these polymers (Yassaa and Williams, 2005, 2007) and because their behavior has been well documented in the past (e.g. Bicchi et al., 2000). Each new fibre was thermally conditioned prior to use according to the manufacturer's recommendations. For this comparison, each of the three fibres was exposed to diluted ( $5 \mathrm{~L} \mathrm{~min}^{-1}$ zero air) $\mathrm{CDS}$ monoterpene standards for $20 \mathrm{~min}$ under static conditions following the previously described flushing procedure.

\subsubsection{Optimisation of the sampling time}

The sampling time was optimized for the $65 \mu \mathrm{m}$ DVB-PDMS fibre coating. Sampling times of 1, 5, 10, 20, 30, 40, 50, 60. 70, 80, 90 and $120 \mathrm{~min}$ were tested. Because DVB-PDMS is an adsorptive-type fibre coating, monoterpenes were extracted under non-equilibrium conditions. The sampling time was chosen as the longest practical time for which the extraction was linear such that even under the most adverse conditions (i.e. highest observed mixing ratio of target monoterpene in plant emission or in the atmosphere), the extraction does not suffer from competitive adsorption. 
Table 2. Detection limits of monoterpenes sampled from glass sampling chamber using DVB-PDMS fibre coating and gas standard bottle.

\begin{tabular}{lr}
\hline Chemical & $\begin{array}{r}\text { Mixing } \\
\text { ratios (ppt) }\end{array}$ \\
\hline$(1 S)-(-)-\alpha$-Pinene & 4 \\
$(1 R)-(+)-\alpha$-Pinene & 4 \\
$\beta$-Myrcene & 5 \\
$(1 S .5 S)-(-)-$ Sabinene & 10 \\
$\delta-3-$ Carene & 6 \\
$(1 R)-(+)-\beta$-Pinene & 5 \\
$(1 S)-(-)-\beta$-Pinene & 5 \\
Cis- $\beta$-Ocimene & 20 \\
$p$-Cymene & 4 \\
(-)-Limonene & 5 \\
$1.8-C i n e o l$ & 8 \\
\hline
\end{tabular}

\subsubsection{Calibration of monoterpenes produced by the CDS}

The mixing ratios of the standards generated by diluting the CDS output with $5 \mathrm{~L} \mathrm{~min}^{-1}$ of hydrocarbon free air, were checked against the response obtained from a certified calibration gas (contents listed in Table 1, National Physical Laboratory, Teddington Middlesex, UK). Relative standard deviations (RSDs) for analyses of both standards are also given in Table 1 along with the estimated theoretical mixing ratios. The difference between the measured and the theoretical concentrations range from 10 to $25 \%$ and were deemed acceptable considering the uncertainties made in the latter calculations.

\subsection{Calibrations curves and limit of detection}

In order to assess at which mixing ratio competitive adsorption occurs for a given fibre, mixing ratios from 3 to $455 \mathrm{ppb}$ of the diluted CDS standard gas were tested using a DVBPDMS fibre coating and a 20 min sampling time under static conditions as previously described. A plot of the mass extracted (mass spectrometer area count) versus mixing ratio shows where competitive adsorption begins.

Diffusion rates of chemicals from vials in the CDS are a function of the vapour pressure of the pure chemical, capillary diameter, capillary length, temperature of the CDS, and the flow rates through each chamber. The ppm values achieved were dictated by the physical limits of the system as constructed and made subsequent dilution to ppt and sub-ppt levels for determination of detection limits impractical. Therefore, the detection limit of the method could not be determined simply by lowering the mixing ratios down to ppt level. For this purpose, the certified gas standard was sequentially diluted with zero-air to values as low as

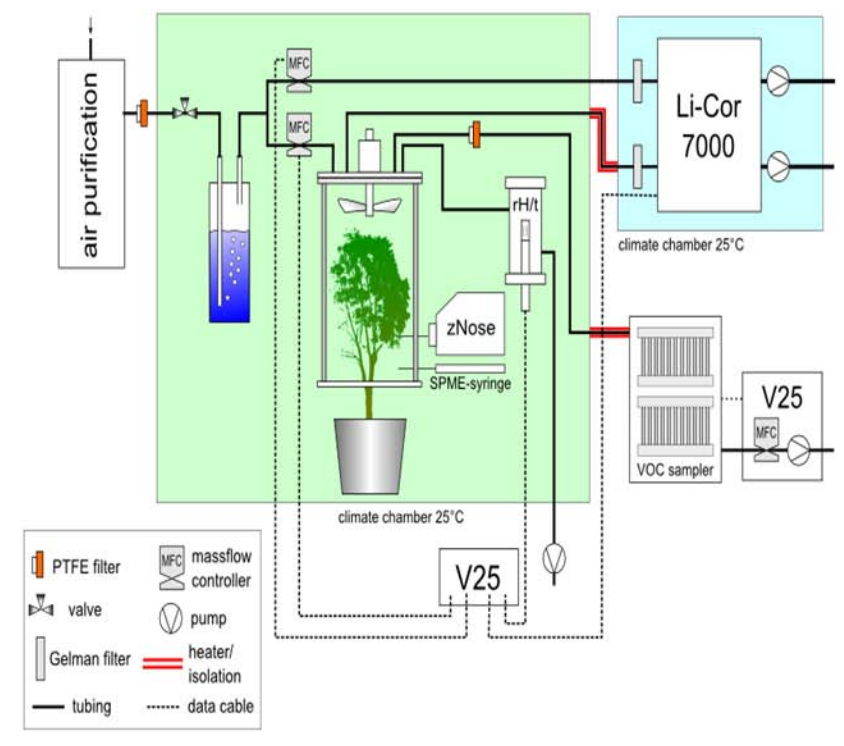

Fig. 2. Overview of the cuvette system. The SPME and zNose are attached to the cuvette system by simply puncturing the Teflon foil with their respective needles.

2 ppt. Detection limits were measured using DVB-PDMS fiber coating and $20 \mathrm{~min}$ sampling time employing the static sampling procedure previously described. The detection limits of target monoterpenes are given in Table 2 and range from 4 to $20 \mathrm{ppt}$.

\subsection{Storage effects}

In order to evaluate the extent of adsorption of monoterpenes on the wall of the glass sampling chamber, it was filled with the monoterpene standard at $20 \mathrm{ppb}$ after dilution with zero air. SPME samples were then taken under static conditions at $0,1,2,3,4,24,48$ and $72 \mathrm{~h}$ after the stopcocks were closed. No significant change in the MS detector response was observed, up to the third day after the chamber was filled (figure not shown). This indicates that there was no significant adsorption of monoterpenes to the walls of the glass sampling chamber.

\subsection{Sampling from whole plant enclosure}

Biogenic emissions of monoterpenes were investigated using an open, dynamic cuvette system installed inside a plant growth chamber. In other words, an air flow ran constantly through the cuvette resulting in steady state conditions mimicking natural outside conditions.

In order to validate the SPME method, monoterpene measurements were simultaneously made by a zNose-GC and also trapped on cartridges which were later analyzed by gas chromatography coupled to flame ionization detection (GC-FID). All tubes and fittings were made of PTFE and PFA Teflon. These materials are chemically inert to the 
relevant VOCs and feature low gas absorption and sequestration properties. Although enclosed plants can stay inside such an enclosure system for a long time without stress, physical and physiological monitoring of the plants was nevertheless performed. An overview of the components of the enclosure system is given in Fig. 2 and the components are described in detail in the following sections.

\subsubsection{Description of cuvette chamber}

Purified compressed air was used to flush the cuvette system. Compressed air was dried via passage through Silica gel cartridges with a moisture indicator (orange gel, $1-3 \mathrm{~mm}$, Merck, Germany). Trace gases, oil vapors, and miscellaneous particles were removed using molecular sieve beads, activated charcoal, and permanganate coated alumina (Type: IAC 630, Purafill, Germany). Glass padding and a PTFEfilter with a pore size of $5 \mu \mathrm{m}$ were used to remove larger particles. The silica gel and molecular sieves were periodically regenerated in a drying oven at $150{ }^{\circ} \mathrm{C}$ and $250^{\circ} \mathrm{C}$, respectively.

The cuvette was a cylindrical chamber of $0.60 \mathrm{~m}$ in height and $0.35 \mathrm{~m}$ in diameter ( $\sim 58 \mathrm{~L}$ internal volume). In the cuvette, all surfaces in contact with sampled air are made of Teflon. The chamber consists of a skeleton of two PVC rings connected by four PVC rods, in which an FEP Teflon foil (Norton, $50 \mu \mathrm{m}$ thickness, Saint-Gobain Performance Plastics, Germany) is fixed. The upper side of the cuvette was closed with a lid whose surface was coated with FEP foil. The applied foil does not show interference with the trace gases tested such as monoterpenes, isoprene, organic acids or sulfur containing compounds, and exhibited only a slight absorption (5-7\%) of photosynthetic active radiation (Kesselmeier et al., 1993, 1996; Schäfer et al., 1992). The cuvette was placed inside a climate controlled chamber. In order to maintain a constant humidity in the cuvette, the air was bubbled through a vessel filled with dionised water. The flow into the cuvette was controlled using a flow controller (MKS Instruments, USA) set to $5 \mathrm{~L} \mathrm{~min}^{-1}$. The air inside the cuvette was mixed by a Teflon coated propeller, driven by a magnetically coupled motor attached to the lid. The climate chamber temperature was set to $25^{\circ} \mathrm{C}$.

\subsubsection{Micrometeorological parameters}

Photosynthetically active radiation (PAR) was measured directly with a Li-Cor quantum sensor $(400-700 \mathrm{~nm}$; Li-Cor Biotechnology, Lincoln, NE, USA) attached to a rod of the cuvette skeleton at plant leaf level to yield realistic values for the irradiation on the leaf surface. When the light in the climate chamber was switched on, PAR values around $550 \mu \mathrm{mol} \mathrm{m}{ }^{-2} \mathrm{~s}^{-1}\left( \pm 25 \mu \mathrm{mol} \mathrm{m}{ }^{-2} \mathrm{~s}^{-1}\right)$ were obtained. Although turning off the lights resulted in an instantaneous drop in radiation, there was a short lag phase in switching on the lights. The PAR conditions were checked for every series of measurements but have been omitted in subsequent Figures for clarity in favor of white (light conditions) and grey (dark conditions) shading.

Humidity and air temperature was measured using a Rotronic humidity/temperature sensor (Hygrometer MP100A, Rotronic Messgeräte GmbH, Germany). The sensor was positioned in a separate chamber which was flushed with air from the cuvette using a custom-made pumping device (MPIC, Mainz, Germany), with a flow rate of $500 \mathrm{~mL} \mathrm{~min}-1$. In order to avoid any radiative heating (greenhouse) effects, the chamber was enveloped with aluminum foil to reflect light.

\subsubsection{Physiological parameters}

Water vapor and $\mathrm{CO}_{2}$ were analyzed online using an infrared dual channel $\mathrm{H}_{2} \mathrm{O} / \mathrm{CO}_{2}$ gas analyzer Li-Cor 7000 (Li-Cor Biotechnology, Lincoln, NE, USA). A custom-made pumping device (MPIC, Mainz, Germany) equipped with a built in analogue rotameter, was used to supply the analyzer with air from the cuvette with a flow rate of $500 \mathrm{~mL} \mathrm{~min}^{-1}$. Small particles were filtered from the air at the inlets of the $\mathrm{Li}_{-}$ Cor using Teflon filters (Zeflour Teflon filters, $2 \mu \mathrm{m}$ pore size, Gelman Science, USA).

\subsubsection{Acclimation of Quercus ilex}

The $Q$. ilex plant tested here was potted in an earthfilled bucket and positioned in the climate chamber (HPS $1500 / 60 / S$, Heraeus-Vötsch) approximately one month before the experiments started. Chamber lights were controlled to simulate day and night conditions, both lasting $12 \mathrm{~h}$, with temperatures of $30^{\circ} \mathrm{C}$ and $20^{\circ} \mathrm{C}$, respectively and relative humidity of $60 \%$ and $50 \%$. The built-in lights of the chamber were switched on during this period, which irradiated the small tree with approximately $500-600 \mu \mathrm{mol} \mathrm{m}^{-2} \mathrm{~s}^{-1}$ PAR. These conditions assured reasonable, i.e. approximately natural emission of monoterpenes.

\subsection{SPME and GC-MS analysis}

The DVB-PDMS fibre coating was exposed to the air inside the whole plant enclosure by simply puncturing the Teflon foil with the SPME needle for 20 min under both light and dark conditions. The experiments were performed over two separate days. The DVB-PDMS response was calibrated under dynamic conditions in the glass SPME sampling chamber (with a flow of $5 \mathrm{~L} \mathrm{~min}^{-1}$ out of the chamber) by diluting the CDS chemical output to $50 \mathrm{ppbv}$ using $5 \mathrm{~L} \mathrm{~min}^{-1}$ of clean air.

Immediately after SPME sampling either from the glass SPME sampling chamber or from the cuvette, the SPME needle was introduced into the split/splitless injector of the gas chromatograph. A glass inlet liner with a narrow internal diameter (0.75 mm I.D., Supelco) was used in order to improve the GC resolution and the peak shape. Desorption was 
achieved in splitless mode at $250^{\circ} \mathrm{C}$ for $5 \mathrm{~min}$. These settings were found to be sufficient for a quantitative desorption of all analytes studied. This was established by subjecting the analysed fibre to a second desorption and observing no carry-over peaks.

The analysis of the samples collected by SPME were conducted using the same procedure described by Yassaa and Williams (2007). Briefly, samples were separated and detected using a gas chromatograph (Agilent Technologies a GC 6890A) coupled to a mass-selective detector (Agilent Technologies MSD 5973 inert). The MS system was operated in electron impact mode with the following conditions: ionization potential $70 \mathrm{eV}$; source temperature $230^{\circ} \mathrm{C}$. The MS system was operated in scan mode $(30-350 u)$ for the identification of compounds and in SIM mode for their quantification. The enantiomeric and non-enantiomeric monoterpenes were separated using a Cyclodex-B capillary column (30 m-long, $0.256 \mathrm{~mm}$ I.D., $0.25 \mu \mathrm{m}$ film thickness) supplied by J \& W Scientific (Folsom, CA, USA). The internal coating was composed of a permethylated $\beta$-cyclodextrin dissolved into a cyanopropyl-dimethyl polysiloxane liquid. At a constant helium carrier gas (Messer Griesheim 6.0) flow rate of $1 \mathrm{~mL} \mathrm{~min}^{-1}$, the column temperature was maintained at $40^{\circ} \mathrm{C}$ for $5 \mathrm{~min}$, then increased to $160^{\circ} \mathrm{C}$ at $1.5^{\circ} \mathrm{C}$ per minute as previously established by Yassaa et al. (2001). The overall analysis time was $52 \mathrm{~min}$.

\section{$2.7 \quad$ zNose analyser}

The zNose (Electronic Sensor Technology; Newbury Park, CA) is a commercially available gas chromatographic analyzer. Besides the detection of explosives and chemical warfare agents (Staples and Viswanathan, 2005), the instrument finds application in several other fields. It is used for food aroma analysis (Lammertyn et al., 2004) or for the ripeness and rot evaluation of fruits ( $\mathrm{Li}$ et al., 2009). It has also found application for the determination of floral aroma compounds of lilac blossom (Oh et al., 2008), alarm pheromone emission from aphids (Schwartzberg et al., 2008) as well as analysis of herbivore-induced plant volatile emissions (Arimura et al., 2005; Kunert et al., 2002).

The zNose 4200 is a miniaturized high-speed gas chromatographic analyzer comprising of a pump, injector, preconcentrating trap, short GC column and a surface acoustic wave (SAW) sensor. A 6-port valve is used to trigger the trap and sensor, respectively. The system draws in a headspace sample at $30 \mathrm{~mL} \mathrm{~min}^{-1}$, which is entrained onto a Tenax trap, where the compounds are adsorbed. The valve is then rotated to align the trap with the column ( $1 \mathrm{~m}$, DB 5, ID $0.25 \mathrm{~mm}$ ID, $0.25 \mu \mathrm{m}$ film thickness). Once aligned, the trap is heated using an electrical current that vaporizes the adsorbed material. A helium carrier gas then transports the material into the column where compounds are separated. The materials exit sequentially and are channeled onto the SAW sensor.

\subsection{VOC sampling on solid adsorbent filled cartridges and analysis with GC-FID}

VOCs were sampled from the cuvette by drawing air through adsorbent filled cartridges at a constant flow rate using a custom-built, automatic cartridge sampling device, constructed at the MPIC Mainz (Kuhn et al., 2005). The system consists of a cartridge magazine comprising two sampling loops with 10 cartridge positions for sampling each, enabling sequential sampling of up to 20 cartridges. Mass flow through distinct cartridges is controlled by two miniaturized sampling valves at the inlet and at the outlet of each cartridge.

VOC sampling and analysis was performed in close accordance with earlier work (Kesselmeier et al., 2002). The cartridges were packed with $130 \mathrm{mg}$ of Carbograph 1 $\left(90 \mathrm{~m}^{2} \mathrm{~g}^{-1}\right)$ followed by $130 \mathrm{mg}$ Carbograph $5\left(560 \mathrm{~m}^{2} \mathrm{~g}^{-1}\right)$, both with a particle size of 20-40 mesh. Carbographs 1 and 5 were provided by Lara s.r.l. (Rome, Italy). The sample flow was set to $200 \mathrm{~mL} \mathrm{~min}^{-1}$ and samples were taken for $15 \mathrm{~min}$ resulting in a sample volume of $3 \mathrm{~L}$.

The analysis of the sample tubes was conducted using a GC-FID system (AutoSystem XL, Perkin-Elmer, USA). Samples were passed into the system using a thermodesorber (TurboMatrix 650, Perkin-Elmer, USA). The sensor was operated isothermally at $300{ }^{\circ} \mathrm{C}$. A HP- 1 column $(100 \mathrm{~m}$, $0.25 \mathrm{~mm}$ ID, $0.5 \mu \mathrm{m}$ film thickness) was flushed with Helium 6.0 (Westfalen AG, Germany) at a flowrate of $1 \mathrm{~mL} \mathrm{~min}^{-1}$. The column temperature program was: $40^{\circ} \mathrm{C}(18 \mathrm{~min})$, $15^{\circ} \mathrm{C} / \mathrm{min}$ to $80^{\circ} \mathrm{C}(40 \mathrm{~min}), 2^{\circ} \mathrm{C} / \mathrm{min}, 150^{\circ} \mathrm{C}, 30^{\circ} \mathrm{C} / \mathrm{min}$, $240^{\circ} \mathrm{C}$ ( $5 \mathrm{~min}$ ). The FID was calibrated using the same VOC gas standard mixture used to calibrate the CDS.

\subsection{Application of SPME method to ambient air}

The potential of SPME for monitoring VOCs in the atmosphere was tested by measuring monoterpenes present in air outside the Max Planck Institute for Chemistry (MPIC, Mainz, Germany) for two days, 14-15 August 2009. Ambient air was pumped at $5 \mathrm{~L} \mathrm{~min}^{-1}$ through a $0.64 \mathrm{~cm}(1 / 4 \mathrm{inch})$ PTFE line from $4 \mathrm{~m}$ height situated directly outside the MPIC and passed through the glass SPME sampling chamber. An ozone scrubber similar to that used in the calibration experiment was installed in the front of the sampling line. After a given time, the stopcocks were closed (static mode) to capture an air sample in the chamber. The DVB-PDMS was then exposed to the enclosed air sample for $20 \mathrm{~min}$. Following each air sample, the fibre was calibrated by sampling monoterpenes from the CDS and analyses were performed by GC-MS as previously described. Parallel measurements of outside air were performed by proton transfer reaction-mass spectrometry. In this technique high number densities of primary $\mathrm{H}_{3} \mathrm{O}^{+}$ions are continuously combined with sample air in a reaction flow drift tube maintained at $2.2 \mathrm{mbar}$ and $50^{\circ} \mathrm{C}$ and $\sim 130 \mathrm{Td}$. Any volatile organic compounds with a proton 


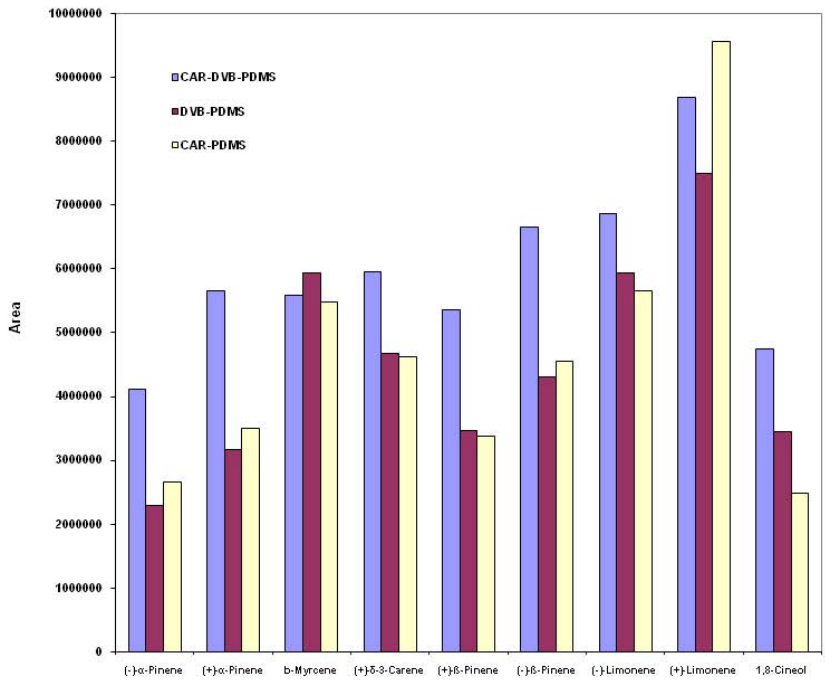

Fig. 3. A comparison of the extraction efficiencies of DVB-PDMS, CAR-PDMS and CAR-DVB-PDMS for monoterpenes.

affinity higher than water react with the primary ions via proton transfer to form protonated ionic products. Primary and product ions are then sampled into a quadrupole mass spectrometer for separation and analysis. Details of the technique have been summarized most recently by Blake et al. (2009). The PTR-MS technique employs no pre-separation of chemicals. As a consequence, a variety of monoterpenes can be found with a protonated mass of $\mathrm{m} / \mathrm{z} 137$ with fragments found at $m / z 81$.

\section{Results and discussion}

\subsection{Comparison of SPME fibre coatings}

As shown in Fig. 3 the three solid SPME fibres efficiently adsorbed the studied monoterpenes. DVB/CAR/PDMS has the highest extraction efficiency for all compounds except for myrcene and (+)-limonene. While DVB-PDMS showed a good adsorption for myrcene, (+)- $\delta$-3-carene, $(+)$ - $\beta$-pinene, $(-)$-limonene and 1.8-cineol, CAR-PDMS showed better relative adsorption of (-)- $\alpha$-pinene, (+)- $\alpha$-pinene, $(-)-\beta$ pinene and (+)-limonene. Interestingly, while (-)-limonene and (+)- $\beta$-pinene were preferentially adsorbed on DVBPDMS, their optical isomers, (+)-limonene and (-)- $\beta$-pinene were better adsorbed on CAR-PDMS. This effect was even more pronounced with limonene enantiomers. The high adsorption efficiency for limonene by CAR-PDMS fibre coating was also reflected in the poor separation of limonene enantiomers (Fig. 4).

Due to the efficient adsorption of $\alpha$-pinene and $\beta$-pinene on the CAR-DVB-PDMS fibre, it becomes readily saturated with these chemicals. Competitive adsorption therefore occurred early for these species (refer to the next section for
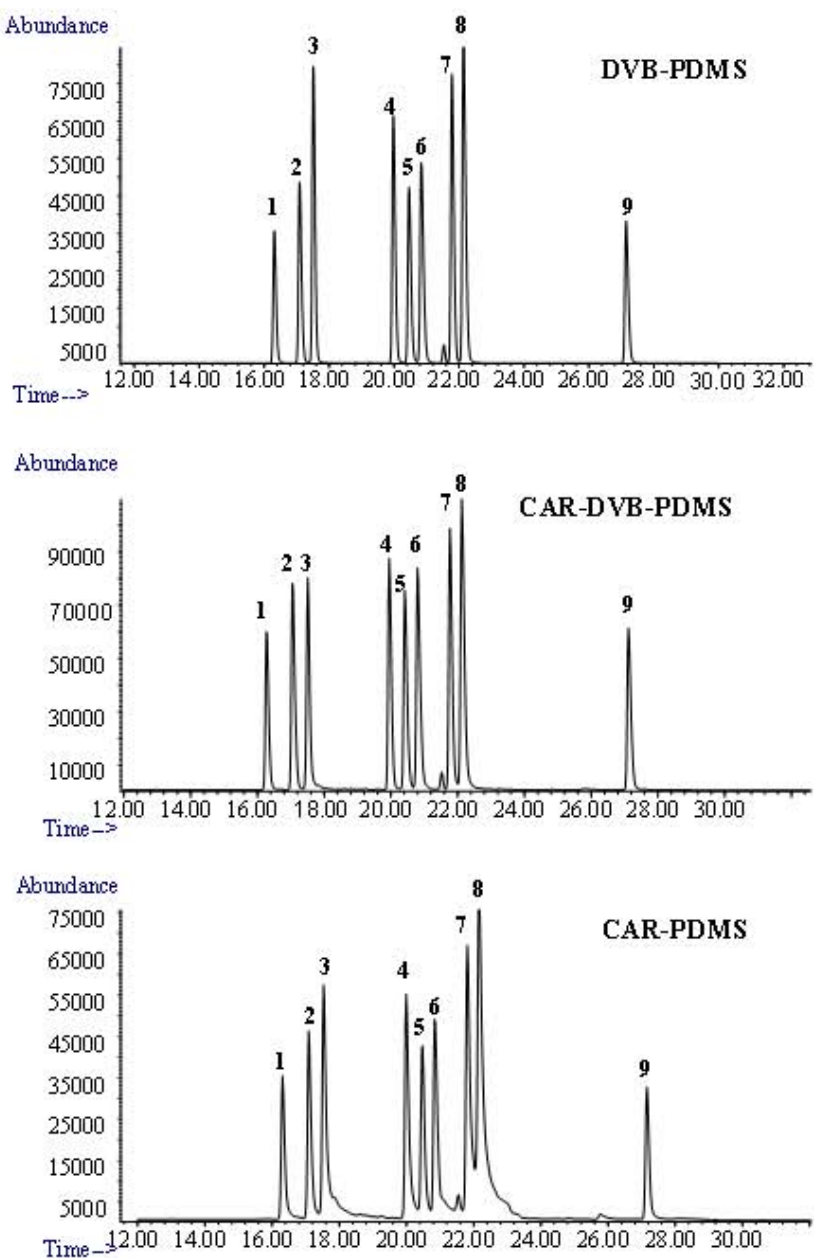

Fig. 4. Reconstructed mass chromatographic profiles $(\mathrm{m} / \mathrm{z}, 93)$ of monotrpenes sampled with three different SPME fibre coatings with 20 min sampling time.(1): (-)- $\alpha$-pinene, (2): (+)- $\alpha$-Pinene, (3): $\beta$-Myrcene, (4): (+)- $\delta$-3-Carene, (5): (+)- $\beta$-Pinene, (6): (-)- $\beta$ Pinene, (7): (-)-Limonene, (8): (+)-Limonene and (9): 1.8-Cineol.

more details on competitive adsorption). This effect is most likely related to the structure and geometry of the molecules and the nature of the interactions between these molecules and the active pores of the SPME solid fibre coatings.

The varying peak tailing observed in Fig. 4 is obviously not related to the GC column separation conditions as a series of optimisation analyses were completed in order to minimize the analysis time and maximize resolution of the enantiomers. These analyses focused on adjustment of the initial temperature of the column and the temperature program, since these two parameters have been previously found to be critical for the beta-cyclodextrin columns (Yassaa et al., 2001). As these optimum separation conditions have been used to test the three SPME fibre coatings, we suggest that this is rather related to the difference in the recovery of adsorbed components which seems to depend on the nature 


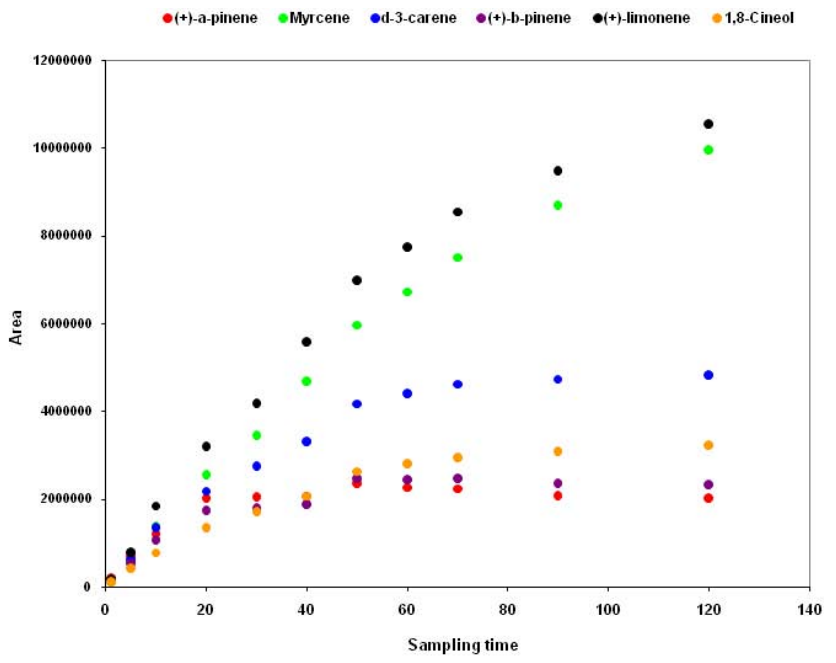

Fig. 5. Extraction kinetics of monoterpenes in 1, 5, 10, 20, 30, 40, 50, 60. 70, 80, 90 and 120 min sampling times using DVB-PDMS.

SPME fiber coating materials. The worst case was obtained when SPME fibre coating was a mixture of carboxen and divinylbenzene.

The best compromise between resolution of enantiomeric pairs and reduction of the effect of competitive adsorption was obtained using DVB-PDMS fibre coating. While DVB phase is mainly mesoporous and ideal for trapping C6-C15 analytes including monoterpenes (C10), CAR is microporous and efficiently traps C2-C6 analytes (Mani, 1999).

\subsection{Optimisation of the sampling time}

DVB-PDMS is an adsorptive SPME fibre coating and is susceptible to competitive adsorption if overloaded. Six extraction times were tested with this SPME fibre coating. The amount of monoterpene extracted is shown in Fig. 5. For the 60, 90 and 120 min extraction times, an increase in the sampling time did not lead to a significant increase in the amount of analyte extracted. This is likely due to the limited adsorptive capacity of the SPME fibre. The 1, 5, 10 and $20 \mathrm{~min}$ sampling times are plotted separately (Fig. 6) along with the results of a linear fit through each. For sampling times between 1 and $20 \mathrm{~min}$, the linearity of the response (here expressed with respect to $R^{2}$ ) ranging between 0.96 and 0.99 , was deemed acceptable for use in quantification. Within the 20 min sampling time, there was no apparent displacement of the compounds and 20 min was therefore chosen as the optimum sampling time for DVB-PDMS fibre coating to quantify monoterpenes.

As can be seen from Fig. 5, $\alpha$-pinene, $\beta$-pinene and 1.8-cineol reach equilibrium earlier than other monoterpene species due to the displacement effect. Such competition on DVB-PDMS can be avoided by limiting sampling to $20 \mathrm{~min}$. It should be noted that in using a DVB-PDMS SPME fibre

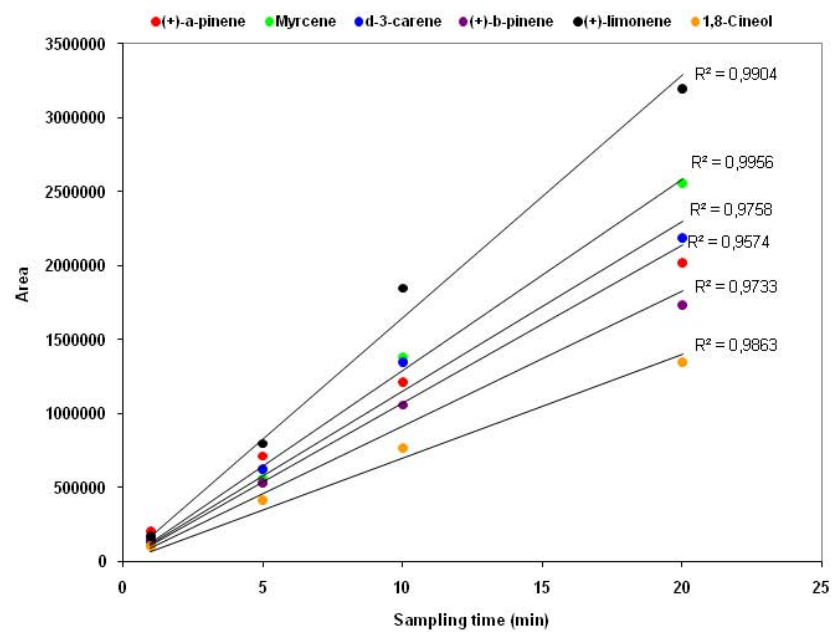

Fig. 6. Extraction kinetics of monoterpenes in 1, 5, 10 and 20 min sampling times and correlation coefficients using DVB-PDMS.

under non-equilibrium conditions, the total response represents the time averaged mixing ratio encountered by the fibre over the course of the sampling period.

\subsection{Calibration curves and detection limits}

The quantification of target monoterpenes was based on the calibration curves for the optimized 20 min sampling time. The mixing ratio ranges of the monoterpenes are shown in Table 3. Except $\alpha$-pinene, which responds linearly only up to around $53 \mathrm{ppb}$, most chemicals respond linearly up to $100 \mathrm{ppb}$ level. Limonene responded linearly up to $300 \mathrm{ppb}$. These results showed how $\alpha$-pinene is affected by the competitive adsorption at high mixing ratios, a fact which should be considered during calibration. Since the maximum measured mixing ratios of the most abundant monoterpene are around a few $\mathrm{ppb}$ in the atmosphere and rarely exceed $50 \mathrm{ppb}$ in plant sampling (Kesselmeier and Staudt, 1999), the limit of linearity range measured in this study is quite acceptable.

The limit of detection showed in Table 2 ranged from $4 \mathrm{ppt}$ for $\alpha$-pinene to $20 \mathrm{ppt}$ for $c i s-\beta$-ocimene. The range of detection limits is quite reasonable and comparable to those obtained in sampling with solid sorbent and thermal desorption.

\subsection{Application to whole plant enclosure}

A $Q$. ilex plant was investigated using SPME, zNose and cartridge VOC sampler side by side. Fig. 7 shows the results of the zNose measurements. The plotted values are the signal peak area of measurements with sample times of $2 \mathrm{~min}$ at $40^{\circ} \mathrm{C}$ sensor temperature. Four signals could be observed, which showed an obvious light dependency with Kovats Indices (KIs) of 988, 1031, 1207 and 1612. Shortly after the light was switched on, emissions of the four compounds could be observed and reached maximum values after approximately $45 \mathrm{~min}$. When the light was turned off, 
Table 3. Calibration curves with correlation coefficients of monoterpenes sampled from the glass sampling chamber using DVB-PDMS and CDS at different mixing ratios.

\begin{tabular}{|c|c|c|c|c|c|c|}
\hline Mixing ratio range (ppb) & $3-15$ & $3-21$ & $3-35$ & $3-53$ & $3-105$ & $3-157$ \\
\hline$(+)-\alpha$-Pinene & $\begin{array}{l}y=188800 \mathrm{x} \\
+308296 \\
R^{2}=0.9992\end{array}$ & $\begin{array}{l}y=168820 \mathrm{x} \\
+430482 \\
R^{2}=0.9896\end{array}$ & $\begin{array}{l}y=128381 \mathrm{x} \\
+808543 \\
R^{2}=0.9505\end{array}$ & $\begin{array}{l}y=90543 \mathrm{x} \\
+1 \mathrm{E}+06 \\
R^{2}=0.876\end{array}$ & $\begin{array}{l}y=47522 \mathrm{x} \\
+2 \mathrm{E}+06 \\
R^{2}=0.7348\end{array}$ & $\begin{array}{l}y=30533 x \\
+3 \mathrm{E}+06 \\
R^{2}=0.6692\end{array}$ \\
\hline Mixing ratio range (ppb) & $12-60$ & $12-80$ & $12-134$ & $12-201$ & $12-402$ & $12-602$ \\
\hline$\beta$-Myrcene & $\begin{array}{l}y=86728 x \\
-260317 \\
R^{2}=0.9989\end{array}$ & $\begin{array}{l}y=85038 x \\
-220729 \\
R^{2}=0.9992\end{array}$ & $\begin{array}{l}y=75910 \mathrm{x} \\
+106226 \\
R^{2}=0.993\end{array}$ & $\begin{array}{l}y=60799 x \\
+839360 \\
R^{2}=0.9611\end{array}$ & $\begin{array}{l}y=38778 \mathrm{x} \\
+2 \mathrm{E}+06 \\
R^{2}=0.8941\end{array}$ & $\begin{array}{l}y=28249 \mathrm{x} \\
+3 \mathrm{E}+06 \\
R^{2}=0.8618\end{array}$ \\
\hline Mixing ratio range (ppb) & $6-33$ & $6-44$ & $6-73$ & $6-110$ & $6-219$ & $6-329$ \\
\hline$(+)-\delta$-3-Carene & $\begin{array}{l}y=133670 \mathrm{x} \\
-28862 \\
R^{2}=0.9994\end{array}$ & $\begin{array}{l}y=123944 x \\
+95667 \\
R^{2}=0.995\end{array}$ & $\begin{array}{l}y=105858 \mathrm{x} \\
+449699 \\
R^{2}=0.9846\end{array}$ & $\begin{array}{l}y=81814 \mathrm{x} \\
+1 \mathrm{E}+06 \\
R^{2}=0.9429\end{array}$ & $\begin{array}{l}y=50130 \mathrm{x} \\
+2 \mathrm{E}+06 \\
R^{2}=0.8654\end{array}$ & $\begin{array}{l}y=34250 \mathrm{x} \\
+3 \mathrm{E}+06 \\
R^{2}=0.804\end{array}$ \\
\hline Mixing ratio range (ppb) & $4-22$ & $4-29$ & $4-49$ & $4-73$ & $4-147$ & $1-220$ \\
\hline$(+)$ - $\beta$-Pinene & $\begin{array}{l}y=143031 x \\
+123372 \\
R^{2}=1\end{array}$ & $\begin{array}{l}y=128183 x \\
+250549 \\
R^{2}=0.9904\end{array}$ & $\begin{array}{l}y=103050 \mathrm{x} \\
+579660 \\
R^{2}=0.9685\end{array}$ & $\begin{array}{l}y=75813 \mathrm{x} \\
+1 \mathrm{E}+06 \\
R^{2}=0.9106\end{array}$ & $\begin{array}{l}y=43009 \mathrm{x} \\
+2 \mathrm{E}+06 \\
R^{2}=0.8048\end{array}$ & $\begin{array}{l}y=28215 \mathrm{x} \\
+2 \mathrm{E}+06 \\
R^{2}=0.7344\end{array}$ \\
\hline Mixing ratio range (ppb) & $9-45$ & $9-61$ & $9-101$ & $9-152$ & $9-303$ & $9-455$ \\
\hline (+)-Limonene & $\begin{array}{l}y=146480 \mathrm{x} \\
-201076 \\
R^{2}=0.9989\end{array}$ & $\begin{array}{l}y=139133 x \\
-71141 \\
R^{2}=0.9975\end{array}$ & $\begin{array}{l}y=122308 \mathrm{x} \\
+383731 \\
R^{2}=0.9902\end{array}$ & $\begin{array}{l}y=97167 x \\
+1 \mathrm{E}+06 \\
R^{2}=0.9568\end{array}$ & $\begin{array}{l}y=62103 x \\
+3 \mathrm{E}+06 \\
R^{2}=0.8929\end{array}$ & $\begin{array}{l}y=44183 \mathrm{x} \\
+5 \mathrm{E}+06 \\
R^{2}=0.8474\end{array}$ \\
\hline Mixing ratio range (ppb) & $7-35$ & $7-50$ & $7-83$ & $7-125$ & $7-250$ & $7-375$ \\
\hline 1.8-Cineol & $\begin{array}{l}y=74551 x \\
+44304 \\
R^{2}=0.9997\end{array}$ & $\begin{array}{l}y=69743 \mathrm{x} \\
+114321 \\
R^{2}=0.9964\end{array}$ & $\begin{array}{l}y=59532 \mathrm{x} \\
+341675 \\
R^{2}=0.9849\end{array}$ & $\begin{array}{l}y=46339 x \\
+739537 \\
R^{2}=0.946\end{array}$ & $\begin{array}{l}y=28534 \mathrm{x} \\
+2 \mathrm{E}+06 \\
R^{2}=0.8696\end{array}$ & $\begin{array}{l}y=19959 \mathrm{x} \\
+2 \mathrm{E}+06 \\
R^{2}=0.8219\end{array}$ \\
\hline
\end{tabular}

the emissions dropped below the detection limit within approximately $15 \mathrm{~min}$. Using the observed KIs, signals can be tentatively assigned to limonene (KI of 1031) and $\beta$-myrcene (KI of 988).

On the other hand, Fig. 8 shows an example of the reconstructed mass chromatographic profile of monoterpenes obtained by analyzing the SPME sample collected from the gaseous emission of $Q$. ilex under light and dark (overlaid in blue) condition on a $\beta$-cyclodextrin column using single ion mode (SIM). The chromatographic profile depicted in Fig. 8 was generated by plotting the current produced by ions with $m / z$ 93, a fragment quite specific to monoterpene hydrocarbons that, in many cases, is the base peak of the mass spectrum. The chromatogram shows only two peaks that are attributed to $\beta$-myrcene and (-)-limonene. By comparing the ratios of $\beta$-myrcene to limonene between SPME GC-MS and zNose, we conclude that the peaks KI 1031 and KI 988 obtained from $\mathrm{zNose}$ during these experiments are very likely limonene and $\beta$-myrcene, respectively.
The SPME (Table 4) and VOC analysis by GC-FID (Fig. 9) showed $\beta$-myrcene as the most prominent chemical emitted, followed by limonene. These two chemicals made up more than $95 \%$ of the total monoterpene emissions. Very small fractions of $\alpha$-pinene, $\beta$-pinene and sabinene, as well as a few other monoterpenes, made up the residual percentages.

While the derived gas exchange rates for limonene from SPME revealed average values of $220 \mathrm{ng} \mathrm{m}^{-2} \mathrm{~s}^{-1}$, the ones from cartridge GC-FID were around $240 \mathrm{ng} \mathrm{m}^{-2} \mathrm{~s}^{-1}$ and those from zNose ranged from 250 to 300 (see, Fig. 10). The gas exchange rates from $\beta$-myrcene were $590 \mathrm{ng} \mathrm{m}^{-2} \mathrm{~s}^{-1} \mathrm{de}-$ rived from SPME and $610 \mathrm{ng} \mathrm{m}^{-2} \mathrm{~s}^{-1}$ obtained from cartridge GC-FID. However, the comparison could not be made with the zNose, because no response factor for myrcene was available.

Previous studies have shown $\alpha$-pinene and $\beta$-pinene as the most prominent compounds emitted by $Q$. ilex with 9,9\% limonene and $6.7 \% \beta$-myrcene found in lesser amounts (Kesselmeier et al., 1996, Yassaa et al., 2001). Three main 
Table 4. Average gas exchange rates $\left(\mathrm{ng} \mathrm{m}^{-2} \mathrm{~s}^{-1}\right.$ ) of monoterpenes from the emission of potted individual of $Q$. ilex obtained with SPME with DVB-PDMS fibre at 20 min sampling during light and dark conditions compared to those recorded by solid sorbent GC-FID and zNose.

\begin{tabular}{lllll}
\hline & $\begin{array}{l}\text { SPME } \\
\text { Light off }\end{array}$ & $\begin{array}{l}\text { SPME } \\
\text { Light on }\end{array}$ & $\begin{array}{l}\text { Solid sorbent } \\
\text { GC-FID }\end{array}$ & zNose \\
\hline$(1 S)-(-)-\alpha$-Pinene & u.d.1. & 1.5 & & \\
$(1 R)-(+)-\alpha$-Pinene & u.d.1. & 0.6 & & \\
$\beta-$ Myrcene & u.d.1. & 592 & 610 & n.q.** \\
$(1 S .5 S)-(-)-S a b i n e n e$ & u.d.1. & 5.5 & & \\
$(1 S)-(-)-C a m p h e n e$ & u.d.1. & 0.2 & & \\
$(1 R)-(+)-\beta-P i n e n e$ & u.d.1. & 0.5 & & $250-300$ \\
$(1 S)-(-)-\beta-P i n e n e$ & u.d.1. & 0.5 & & \\
Cis- $\beta$-Ocimene & u.d.1. & 0.5 & & \\
$(4 S)-(-)-$ Limonene & 0.6 & 223 & 240 & \\
$(4 R)-(+)-$ Limonene & u.d.1. & 1.0 & & \\
$1.8-C i n e o l$ & u.d.1. & 0.3 & & \\
\hline
\end{tabular}

* u.d.l.: under detection limit. ** n.q.: detected but not quantified.

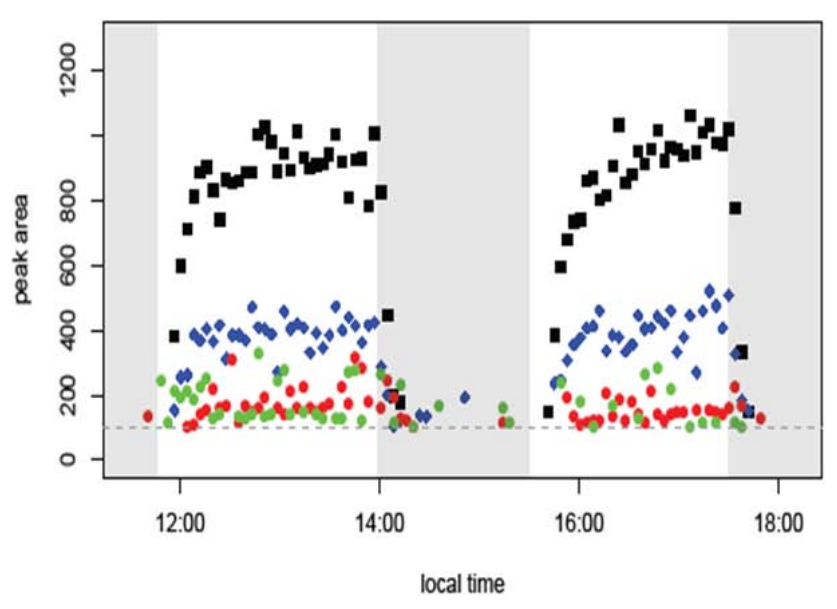

Fig. 7. Emissions of the potted $Q$. ilex, measured in the cuvette with sample times of $3 \mathrm{~min}$ at $40^{\circ} \mathrm{C}$ sensor temperature of the zNose. The dashed line indicates the peak detection limit. i KI 988, m KI 1031, Y KI 1207, Y KI 1612. Fig. 10. Limonene calculated gas exchange rates for the zNose data (m), KI 1031 compared to rates obtained by solid sorbent GC-FID data $(\mathrm{m})$. The dashed line indicates the peak detection limit of zNose.

emission types of $Q$. ilex have been distinguished in literature. Of investigated populations, $70.5 \%$ emitted mainly $\alpha$ pinene and $\beta$-pinene (60-80\%), $21.2 \%$ produced higher proportions of limonene (30-80\%), and $8.2 \%$ had higher proportions of $\beta$-myrcene (60-90\%) in their emissions (Staudt et al., 2001). The observed monoterpene emissions were therefore not exceptional and simply reflect the different emitter types of this species.

The exchange rates of the potted individual enclosed in the cuvette showed similar results for $\beta$-myrcene by the three techniques and by SPME and GC-FID for limonene. The observed emission rates were comparable and fit into the range

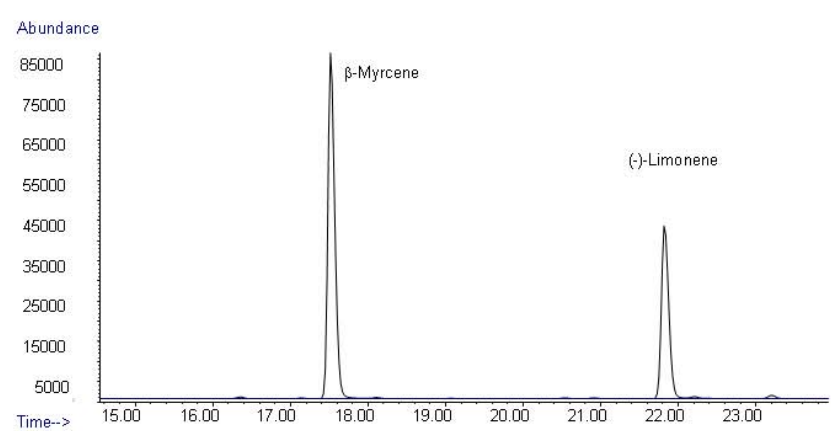

Fig. 8. Reconstructed mass chromatographic profiles $(\mathrm{m} / \mathrm{z}, 93)$ of monoterpenes present in the emission of potted $Q$. ilex during light and dark ((overlaid in blue) conditions.

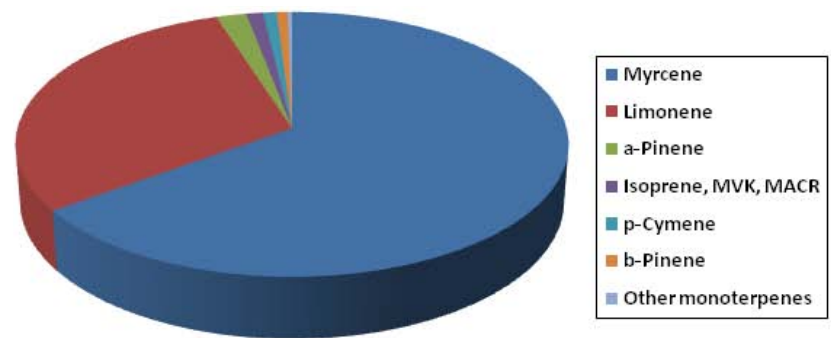

Fig. 9. Composition of monoterpenes emitted by the potted individual of $Q$. ilex according to solid sorbent GC-FID measurements.

of reported total monoterpene emission rates of $Q$. ilex. This value is generally between 10 and $1600 \mathrm{ng} \mathrm{m}^{-2} \mathrm{~s}^{-1}$ depending on the individual plant, season, and measurement conditions (Staudt et al., 2001).

It should be noted that the studied $Q$. ilex individual showed a strong enantiomeric preference (almost $100 \%(-)-$ limonene) compared to the previously investigated species 


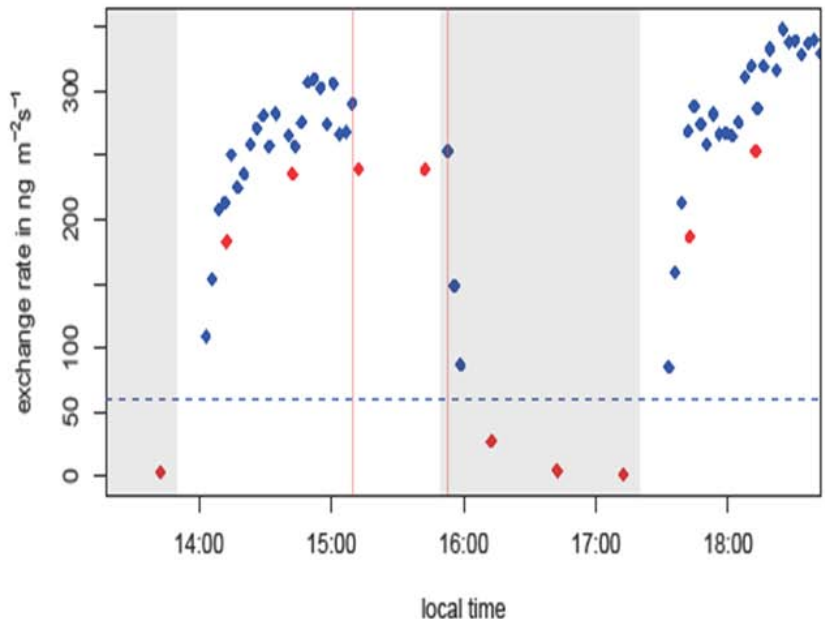

Fig. 10. Limonene calculated gas exchange rates for the zNose data (m), KI 1031 compared to rates obtained by solid sorbent GCFID data (m). The dashed line indicates the peak detection limit of zNose.

by Yassaa et al. (2001) where (-)-limonene and (+)limonene accounted 41 and 59\%, respectively.

\subsection{Application to ambient air}

The mixing ratios of monoterpenes in the ambient air of outside of MPIC (Mainz, Germany) at $4 \mathrm{~m}$ height were determined over two days. The samples were taken by filling the $5 \mathrm{~L}$ glass SPME sampling chamber using a pump. Both ambient air and calibration gas were sampled with SPME under static conditions with the two valves closed and a sample time of $20 \mathrm{~min}$. Parallel measurements were performed with proton transfer reaction-mass spectrometry with $\mathrm{m} / \mathrm{z} 137$ used to quantify monoterpenes. Since PTR-MS is not selective for monoterpenes, only the mixing ratios of total monoterpenes could be determined for comparison.

Table 5 reports the min, max and average of 2 days (1415 August 2009) of measurements of monoterpenes in ambient air outside of MPIC (Mainz, Germany). The total mixing ratios of monoterpenes by PTR-MS, 600 pptv was close to that determined by SPME (425 pptv as the sum of the identified and quantified monoterpenes). This provides additional support for the applicability of the SPME system to the measurement of monoterpenes in the atmosphere.

\section{Conclusions}

Using optimised 20 min sampling times and conditions with a DVB-PDMS fibre coating, SPME has shown good potential for studying BVOCs both in a plant chamber and in the atmosphere. Emission rates of monoterpenes from a potted individual of $Q$. ilex determined by SPME are comparable to
Table 5. Average monoterpene mixing ratios (pptv) of monoterpenes present in the ambient air outside MPIC (Mainz, Germany) sampled with SPME, 14-15 August 2009.

\begin{tabular}{lccc}
\hline & Min & Max & Average \pm RSD $\%$ \\
\hline$(1 S)-(-)-\alpha$-Pinene & 60 & 65 & $64 \pm 5$ \\
$(1 R)-(+)-\alpha$-Pinene & 49 & 56 & $53 \pm 6$ \\
$\beta-$ Myrcene & 22 & 24 & $24 \pm 3$ \\
$(+)-\delta$-3-Carene & 45 & 51 & $49 \pm 6$ \\
$(1 R)-(+)-\beta$-Pinene & 32 & 45 & $40 \pm 18$ \\
$(1 S)-(-)-\beta$-Pinene & 52 & 62 & $58 \pm 9$ \\
$(4 S)-(-)$-Limonene & 31 & 36 & $35 \pm 8$ \\
$(4 R)-(+)-$ Limonene & 36 & 40 & $39 \pm 6$ \\
$1.8-$ Cineol & 57 & 61 & $59 \pm 3$ \\
\hline
\end{tabular}

rates found by the zNose and through use of solid sorbent and GC-FID.

Although it has been shown that the zNose can qualitatively measure the emission potential and kinetics of plant volatile emission, chemical speciation must be confirmed using alternative methods. SPME represents the technique of choice for this purpose. Compared to cartridge based adsorption and thermal desorption techniques, SPME is cheap, simple, fast, sensitive. It is highly mobile, completely eliminates the use of organic solvents, and does not require the use of an expendable cryogen in the analysis. This is easily automated method when combined with a portable and fast GC. These qualities should provide excellent opportunities for studying emissions of organic volatiles from a variety of different plant species, both in plant chambers and in ambient air.

Acknowledgements. The authors would like to thank Uwe Kuhn, Tamara Dindorf, Thomas Kenntner, Frank Helleis and NinaMaria Knothe from Biogeochemistry Department, Max-Planck Institute for Chemistry for their technical support in constructing the permeation device.

The service charges for this open access publication have been covered by the Max Planck Society.

Edited by: D. Riemer

\section{References}

Arimura, G., Kost, C., and Boland, W.: Herbivore-induced, indirect plant defences, Biochim. Biophys. Acta - Mol. Cell Biol. Lip., 1734, 91-111, 2005.

Baldwin, I. T., Halitschke, R., Paschold, A., von Dahl, C. C., and Preston, C. A.: Volatile Signaling in Plant-Plant Interactions: "Talking Trees" in the Genomics Era., Science, 311, 812-815, 2006. 
Baker, B. and Sinnott, M.: Analysis of sesquiterpene emissions by plants using solid phase microextraction, J. Chromatogr. A, 1216, 8442-8451, 2009.

Bicchi, C., Drigo, S., and Rubiolo, P.: Influence of fibre coating in the headspace solid-phase microextraction-gas chromatographic analysis of aromatic and medicinal plants, J. Chromatogr. A, 892, 469-485, 2000.

Blake, R. S., Monks, P. S., and Ellis, A. M.: Proton-Transfer Reaction Mass Spectrometry, Chem. Rev., 109, 861-896, doi:10.1021/cr800364q, 2009.

Croteau, R.: Biosynthesis and catabolism of monoterpenoids, Chem. Rev., 87, 929-954, 1987.

Guenther, A., Hewitt, C. N., Erickson, D., Fall, R., Geron, C., Graedel, T., Harley, P., Klinger, L., Lerdau, M., Mckay, W. A., Pierce, T., Scholes, B., Steinbrecher, R., Tallamraju, R., Taylor, J., and Zimmerman, P.: A global-model of natural volatile organic compound emissions, J. Geophys. Res., 100, 8873-8892, 1995.

Helmig, D., Revermann, T., Pollmann, J., Kaltschmidt, O., Hernandex, A. J., Bocquet, F., and David, D.: Calibration system and analytical considerations for quantitative sesquiterpene measurements in air, J. Chromatogr. A , 1002, 193-211, 2003.

Kesselmeier, J., Meixner, F. X., Hofmann, U., Ajavon, A.-L., Leimbach, S., and Andreae, M. O.: Reduced sulfur compound exchange between the atmosphere and tropical tree species in southern Cameroon, Biogeochem., 23, 23-45, 1993.

Kesselmeier, J., Schäfer, L., Ciccioli, P., Brancaleoni, E., Cecinato, A., Frattoni, M., Foster, P., Jacob, V., Denis, J., Fugit, J. L., Dutaur, L., and Torres, L.: Emission of monoterpenes and isoprene from a Mediterranean oak species Quercus ilex L. measured within the BEMA (Biogenic Emissions in the Mediterranean Area) project, Atmos. Environ., 30, 1841-1850, 1996.

Kesselmeier, J., Bode, K., Hofmann, U., Mueller, H., Schaefer, L., Wolf, A., Ciccioli, P., Brancaleoni, E., Cecinato, A., Frattoni, M., Foster, P., Ferrari, C., Jacob, V., Fugit, J. L., Dutaur, L., Simon, V., and Torres, L.: Emission of short chained organic acids, aldehydes and monoterpenes from Quercus ilex L. and Pinus pinea L., in relation to physiological activities, carbon budget and emission algorithms, Atmos. Environ., 31(SI), 119-134, 1997.

Kesselmeier, J. and Staudt, M.: Biogenic volatile organic compounds (VOC): An overview on emission, physiology and ecology, J. Atmos. Chem., 33, 23-88, 1999.

Kesselmeier, J., Kuhn, U., Rottenberger, S., Biesenthal, T., Wolf, A., Schebeske, G., Andreae, M. O., Ciccioli, P., Brancaleoni, E., Frattoni, M., Oliva, S. T., Botelho, M. L., Silva, C. M. A., and Tavares, T. M.: Concentrations and species composition of atmospheric volatile organic compounds (VOC) as observed during the wet and dry season in Rondônia (Amazonia), J. Geophys. Res., 107, 8053, doi:10.1029/2000JD000267, 2002.

Kuhn, U., Rottenberger, S., Biesenthal, T., Wolf, A., Schebeske, G., Ciccioli, P., Brancaleoni, E., Frattoni, M., Tavares, T. M., and Kesselmeier, J.: Isoprene and monoterpene emissions of Amazonian tree species during the wet season: Direct and indirect investigations on controlling environmental functions, J. Geophys. Res., 107(D20), 8071, doi:10.1029/2001JD000978, 2002.

Kuhn, U., Dindorf, T., Ammann, C., Rottenberger, S., Guyon, P., Holzinger, R., Ausma, S., Kenntner, T., Helleis, F., and Kesselmeier, J.: Design and field application of an automated cartridge sampler for VOC concentration and flux measurements. J. Environ. Monit., 7, 568-76, 2005.

Kunert, M., Biedermann, A., Koch, T., and Boland, W.: Ultrafast sampling and analysis of plant volatiles by a hand-held miniaturised GC with pre-concentration unit: Kinetic and quantitative aspects of plant volatile production, J. Sep. Sci., 25, 677-684, 2002.

Lammertyn, J., Veraverbeke, E. A., and Irudayaraj, J.: zNoseTM technology for the classification of honey based on rapid aroma profiling. Sensors and Actuators B: Chemical, 98, 54-62, 2004.

Li, Z., Wang, N., Raghavan, G. V., and Vigneault, C.: Ripeness and rot evaluation of "Tommy Atkins" mango fruit through volatiles detection, J. Food Engin., 91, 319-324, 2009.

Lough, W. J. and Wainer, I. W.: Chirality in Natural and Applied Science, CRC Press, Blackwell Publishing, Oxford, 2002.

Mani, V.: Properties of commercial SPME coatings. In applications of Solid Phase Microextraction, Pawliszyn, J., Ed., The Royal Society of chemistry, Cambridge, UK, 57-108, 1999.

Müller, J. F.: Geographical distribution and seasonal variation of surface emissions and deposition velocities of atmospheric trace gases, J. Geophys. Res., 97, 3787-3804, 1992.

Oh, S. Y., Ko, J. W., Jeong, S.-Y., and Hong, J.: Application and exploration of fast gas chromatography-surface acoustic wave sensor to the analysis of thymus species, J. Chromatogr. A, 1205, 117-127, 2008.

Pollmann, J., Ortega, J., and Helmig, D.: Analysis of atmospheric sesquiterpenes: sampling losses and mitigation of ozone interference, Environ. Sci. Technol., 39, 9620-9629, 2005.

Schäfer, L., Kesselmeier, J., and Helas, G.: Formic and Acetic acid emission from conifers measured with a "cuvette" technic, in: $\mathrm{CeC}$ Air Pollution Research 39: Field Measurements and Interpretation of Species Related to Photooxidants and Acid Deposition, edited by: Angeletti, G., Beilke, S., and Slanina, J., Eur. Comm., Brussels., 319-323, 1992.

Schwartzberg, E., Kunert, G., Stephan, C., David, A., Röse, U., Gershenzon, J., Boland, W., and Weisser, W.: Real-time analysis of alarm pheromone emission by the pea aphid (Acyrthosiphon pisum) under predation. J. Chem. Ecol., 34, 76-81, 2008.

Staples, E. and Viswanathan, S.: Ultrahigh-speed chromatography and virtual chemical sensors for detecting explosives and chemical warfare agents, Sensors J., IEEE, 5, 622-631, 2005.

Staudt, M., Mandl, N., Joffre, R., and Rambal, S.: Intraspecific variability of monoterpene composition emitted by Quercus ilex leaves, Can. J. Forest Res., 31, 174-180, 2001.

Stokes, G. Y., Chen, E. H., Buchbinder, A. M., Paxton, W. F., Keeley, A., and Geiger, F. M.: Atmospheric heterogeneous stereochemistry, J. Amer. Chem. Soc. 131, 13733-13737, 2009.

Williams, J.: Organic trace gases: An overview, Environ. Chem., 1, 125-136, 2004.

Williams, J., Yassaa, N., Bartenbach, S., and Lelieveld, J.: Mirror image hydrocarbons from Tropical and Boreal forests, Atmos. Chem. Phys., 7, 973-980, doi:10.5194/acp-7-973-2007, 2007.

Unsicker, S. B., Kunert, G., and Gershenzon, J.: Protective perfumes: the role of vegetative volatiles in plant defense against herbivores. Cur. Opinion Plant Biol. 12, 479-485, 2009.

Yassaa, N., Meklati, B. Y., and Cecinato, A.: Evaluation of monoterpenic biogenic volatile organic compounds in ambient air around Eucalyptus globulus, Pinus halepensis and Cedrus atlantica trees growing in Algiers city area by chiral and achiral 
capillary gas chromatography, Atmos. Environ., 34, 2809-2816, 2000.

Yassaa, N., Brancaleoni, E., Frattoni, M., and Ciccioli, P.: Trace level determination of enantiomeric monoterpenes in terrestrial plant emission and in the atmosphere using a $\beta$-cyclodextrin capillary column coupled with thermal desorption and mass spectrometry, J. Chromatogr. A, 915, 185-197, 2001.
Yassaa, N. and Williams, J.: Analysis of enantiomeric and nonenantiomeric monoterpenes in plant emissions using portable dynamic air sampling/solid-phase microextraction (PDAS-SPME) and chiral gas chromatography/mass spectrometry, Atmos. Environ., 39, 4875-4884, 2005.

Yassaa, N. and Williams, J.: Enantiomeric monoterpene emissions from natural and damaged Scots pine in a boreal coniferous forest measured using solid-phase microextraction and gas chromatography/mass spectrometry, J. Chromatogr. A, 1141, 138$144,2007$. 